\title{
Neprilysin, obesity and the metabolic syndrome
}

\author{
Kristina F. Standeven, $\mathrm{PhD}^{\#, \dagger}$, Katharina Hess, $\mathrm{MD}^{\#, \dagger}$, Angela M. Carter, $\mathrm{PhD}^{\dagger}$, Gillian I. \\ Rice, $\mathrm{PhD}^{\star}, \dagger$, Paul A. Cordell, $\mathrm{PhD}^{\dagger}$, Anthony J. Balmforth, $\mathrm{PhD}^{\dagger}$, Bao Lu ${ }^{\&}$, D. Julian Scott, \\ MD $^{\dagger}$, Anthony J. Turner, PhD ${ }^{*}$, Nigel M. Hooper, PhD*, and Peter J. Grant, MD ${ }^{\dagger}$ \\ tDivision of Cardiovascular and Diabetes Research, Leeds Institute of Genetics, Health and \\ Therapeutics, University of Leeds, Leeds LS2 9JT, UK \\ "Proteolysis Research Group, Institute of Molecular and Cellular Biology, Faculty of Biological \\ Sciences, and Leeds Institute of Genetics, Health and Therapeutics, University of Leeds, Leeds \\ LS2 9JT, UK \\ \&Children's Hospital, Harvard Medical School, Boston, MA, USA
}

\begin{abstract}
Objective-Neprilysin (NEP), a zinc metallo-endopeptidase, has a role in blood pressure control and lipid metabolism. The present study tested the hypothesis that NEP is associated with insulin resistance and features of the metabolic syndrome (MetS) in a study of 318 healthy human subjects and in murine obesity and investigated NEP production by adipocytes in-vitro.

Methods and Results-In 318 white European males, plasma NEP was elevated in the MetS and increased progressively with increasing MetS components. Plasma NEP activity correlated with insulin, homeostasis model assessment and body mass index in all subjects $(\mathrm{p}<0.01)$. Quantitative RT-PCR and Western blotting showed that in human pre-adipocytes NEP expression is upregulated 25-30 fold during differentiation into adipocytes. Microarray analysis of mRNA from differentiated human adipocytes confirmed high NEP expression comparable to adiponectin and plasminogen activator inhibitor-1. In a murine model of diet-induced insulin resistance, plasma NEP levels were significantly higher in high fat diet (HFD)-fed compared with normal chow diet (NCD)-fed animals ( $1642 \pm 529$ and $820 \pm 487 \mathrm{pg} / \mu \mathrm{l}$, respectively; $\mathrm{p}<0.01)$. Tissue NEP was increased in mesenteric fat in HFD compared with NCD-fed mice $(\mathrm{p}<0.05)$. NEP knock out mice did not display any changes in insulin resistance, glucose tolerance or body and epididymal fat pad weight compared to wild type mice.
\end{abstract}

Conclusions-In humans, NEP activity correlated with body mass index and measures of insulin resistance with increasing levels in subjects with multiple cardiovascular risk factors. NEP protein production in human adipocytes increased during cell differentiation and plasma and adipose tissue levels of NEP were increased in obese insulin resistant mice. Our results indicate that NEP associates with cardio-metabolic risk in the presence of insulin resistance and increases in obesity.

\section{Keywords}

insulin resistance; obesity; metabolic syndrome; cardiovascular disease; neprilysin

Corresponding Author: Professor Peter J. Grant, Division of Cardiovascular and Diabetes Research, Leeds Institute of Genetics, Health and Therapeutics, LIGHT Laboratories, Clarendon Way, University of Leeds, Leeds LS2 9JT, UK. Telephone: 01133437721 , Facsimile: 0113343 7738, P.J.Grant@leeds.ac.uk.

\#Joint first author

Conflict of interest: The authors declare no conflict of interest. 


\section{Introduction}

Neprilysin (NEP, neutral endopeptidase, EC3.4.24.11) is a mammalian integral membrane zinc metallo-endopeptidase widely expressed on the surface of a variety of cells, including endothelial, epithelial and smooth muscle cells, cardiac myocytes and fibroblasts.(1;2) NEP cleaves peptides at the $\mathrm{N}$-terminal side of hydrophobic amino acid residues and is responsible for the degradation and inactivation of a number of bioactive peptides, including endothelins, angiotensins I and II, bradykinin, atrial natriuretic peptide, enkephalins, substance $\mathrm{P}$ and chemotactic peptides. The vasopeptidase inhibitor omapatrilat simultaneously inhibits angiotensin converting enzyme (ACE) and NEP (3-5), and in normotensive volunteers and hypertensive subjects omapatrilat produced greater decreases in systolic, and diastolic pulse pressure than ACE inhibition alone (6;7), indicating that NEP might have a role in blood pressure regulation.

NEP is also produced by adipocytes (8), raising the possibility that it might have a role as an adipokine regulating aspects of adipocyte function. In support of this, inhibition of NEP in obese insulin-resistant Zucker rats improved whole body insulin-mediated glucose disposal, and dual ACE/NEP inhibition induced profound insulin sensitization and increased myocardial glucose uptake.(9-11) These latter studies suggest that NEP directly contributes to the development of insulin resistance.

A soluble form of NEP is present in plasma and levels have been measured in several studies.(12-15) Recently we determined the heritability of plasma NEP and its contribution to variance in systolic blood pressure (SBP) and diastolic blood pressure (DBP) in the Leeds Family Study. In addition to associations of NEP with SBP and DBP, we observed correlations of NEP with body mass index (BMI), cholesterol, and triglycerides.(16)

The results of these studies indicate that NEP associates with the regulation of insulin resistance, blood pressure and lipid metabolism. To investigate this association further, we studied i) the clinical relationship between NEP activity, obesity, insulin resistance and components of the metabolic syndrome in 318 healthy individuals characterised for insulin resistance using the homeostasis model assessment and the presence of the metabolic syndrome (MetS) according to the International Diabetes Federation (IDF) definition, ii) the expression of NEP in human Simpson-Golabi-Behmel syndrome (SGBS) adipocytes during differentiation in vitro, iii) the effect of diet-induced insulin resistance and obesity on plasma and tissue NEP levels in a murine model and iv) metabolic characteristics of NEP knock out (NEPKO) mice.

\section{Materials and Methods}

\section{i) Clinical Study of Healthy Volunteers}

Subjects-The study population comprised 318 clinically healthy white males of European origin, characterised for the presence of the MetS and in whom stored plasma was available for analysis of NEP. Participant recruitment has been published previously $(17 ; 18)$. In brief, all subjects were free from clinical cardiovascular disease or previously diagnosed diabetes. Fasting venous blood samples were taken for analysis of lipid sub-fractions, glucose and insulin and haemostatic factors as previously described. SBP and DBP, mean of 3 readings, were measured to the nearest $2 \mathrm{~mm} \mathrm{Hg}$ with subjects in a sitting position. All subjects gave informed consent according to a protocol approved by the Leeds Teaching Hospitals Trust Research Ethics Committee, in accordance with institutional guidelines and the Declaration of Helsinki. 
Biochemical analyses-Analysis of fasting lipids, glucose, insulin and homeostasis model assessment (HOMA), tissue plasminogen activator (tPA) and plasminogen activator inhibitor-1 (PAI-1) were carried out as previously described.(17;18)NEP was assayed according to an original protocol (19) modified in our laboratory using the fluorogenic substrate succinoyl-Ala-Ala-Phe-7-amido-4-methylcoumarin $(200 \mu \mathrm{M})$ in a coupled assay with leucine aminopeptidase $(50 \mu \mathrm{g} / \mathrm{ml})$ in $50 \mathrm{mM}$ Hepes $/ \mathrm{NaOH}, 200 \mathrm{mM} \mathrm{NaCl}, 10 \mu \mathrm{M}$ $\mathrm{ZnCl}_{2}, 1 \%$ DMSO, $\mathrm{pH} 6.8$ at room temperature in the dark. Fluorescence was measured using a Biotek Synergy HT plate reader $\left(\lambda_{\text {excitation }}=380 \mathrm{~nm}\right.$ and $\left.\lambda_{\text {emission }}=460 \mathrm{~nm}\right)$. Enzyme activity (relative fluorescence units) in the plasma sample was converted to a concentration of enzyme by reference to a standard curve of recombinant human NEP (R\&D Systems, UK) assayed under the same conditions. The lower limit of detection for this assay was $0.0027 \mathrm{nmol} \mathrm{NEP/L}$. The inter- and intra-assay coefficients of variation were $6.9 \%$ and $2.5 \%$, respectively.

Definition of metabolic syndrome-Presence of the metabolic syndrome was defined according to the IDF criteria (20) as waist circumference $\geq 94 \mathrm{~cm}$ (MetS IDF waist) plus any two of the following: triglycerides $\geq 1.7 \mathrm{mmol} / \mathrm{L}$ (MetS $\mathrm{SIF}_{\mathrm{IDF}} \mathrm{TG}$ ); high density lipoprotein (HDL) cholesterol $<1.03 \mathrm{mmol} / \mathrm{L}\left(\mathrm{MetS}_{\mathrm{IDF}} \mathrm{HDL}\right)$; treatment of previously diagnosed hypertension or SBP $\geq 130 \mathrm{~mm} \mathrm{Hg}$ or DBP $\geq 85 \mathrm{~mm} \mathrm{Hg}$ (MetS $\left.\mathrm{SDF}_{\mathrm{IDT}} \mathrm{HT}\right)$; fasting glucose $\geq$ $5.6 \mathrm{mmol} / \mathrm{L}$ or previously diagnosed type 2 diabetes (Met $\mathrm{S}_{\mathrm{IDF}} \mathrm{DM} / \mathrm{IFG}$ ).

\section{ii) Cell and Murine Studies}

\section{Neprilysin expression in differentiating human Simpson-Golabi-Behmel syndrome (SGBS) cells}

Cell culture: Human SGBS pre-adipocytes, originally derived from the stromal fraction of subcutaneous adipose tissue of an infant with SGBS, were cultured as described previously $(21 ; 22)$. Briefly, SGBS preadipocytes were maintained in DMEM/Ham's F12 (1:1) culture medium containing $10 \%$ foetal bovine serum, $8 \mathrm{mg} / \mathrm{ml}$ biotin, $4 \mathrm{mg} / \mathrm{ml}$ pantothenate, $100 \mathrm{U} /$ $\mathrm{ml}$ penicillin and $100 \mathrm{mg} / \mathrm{ml}$ streptomycin. To obtain basal serum-free medium (OF medium), supplementation of foetal bovine serum was omitted. Cells were seeded into the appropriate sterile plastic at 4000 cells per $\mathrm{cm}^{2}$, incubated at $37^{\circ} \mathrm{C}$ in a humidified atmosphere containing $5 \% \mathrm{CO}_{2} / 95 \% \mathrm{O}_{2}$ and grown to confluence. After reaching confluence (day 0), adipogenic differentiation was induced by incubation with OF medium supplemented with $10 \mathrm{mg} / \mathrm{ml}$ apo-transferrin, $20 \mathrm{nM}$ recombinant human insulin, $0.1 \mathrm{mM}$ hydrocortisone and $200 \mathrm{pM}$ triiodo-L-thyronine (T3). For the first 4 days, this adipogenic culture medium was additionally supplemented with $25 \mathrm{nM}$ dexamethasone, $0.5 \mathrm{mM}$ IBMX and $2 \mathrm{mM}$ rosiglitazone. Cell medium was changed on days 4 and 9 . Cells were used between passages 31-36.

Microarray Analysis: Human Genome U133 Plus 2.0 array (Affymetrix) was used for mRNA expression profiling. Total RNA was extracted from 14 day differentiated SGBS cells using a TRIzol Plus RNA purification kit (Invitrogen, UK) according to the manufacturers instructions. First and second strand cDNA were synthesized from $3 \mu \mathrm{g}$ of total RNA, in vitro transcribed, and fragmented using the recommended Affymetrix reagents and kits. Samples were hybridized to the HG-U133 Pus 2.0 array, processed by the fluidics station and scanned using an Affymetrix GeneChip Scanner 3000. The captured images were analysed using Affymetrix GeneChip Operating Software (GCOS) v 1.4.

Total RNA isolation and real-time RT-PCR: Total RNA was isolated by TRIzol extraction as described above. Samples were taken every two days, starting on day 0 (undifferentiated) to 14 days differentiation. Reverse transcription was carried out using a TaqMan Reverse Transcription Kit (Applied Biosystems, UK) and real-time quantitative 
PCR was performed with an ABI 7900HT Sequence Detection System (Applied

Biosystems) using the TaqMan Universal PCR Master Mix protocol. Primers and TaqMan

probe for the human NEP gene were obtained from Applied Biosystems as a TaqMan Gene Expression Assay (Assay I.D. Hs00153519_m1). Forward and reverse primers for human GAPDH $\left(5^{\prime}-\right.$ GCTCCTCCTGTTCGACAGTCA-3' and $5^{\prime}-$

ACCTTCCCCATGGTGTCTGA- $3^{\prime}$, respectively) were obtained from Invitrogen. The TaqMan probe for human GAPDH (VIC-5' -TTCTTTTGCGTCGCCAGCCGAG-3' -

TAMRA) was custom synthesised by Applied Biosystems. All reactions were carried out in triplicate. PCR cycling conditions were as follows: $95^{\circ} \mathrm{C}$ for $10 \mathrm{~min}$ followed by 40 cycles of $95^{\circ} \mathrm{C}$ for $15 \mathrm{~s}$ and $60^{\circ} \mathrm{C}$ for $1 \mathrm{~min}$. NEP mRNA levels were normalized to the values of the endogenous control GAPDH and the results expressed as fold changes relative to undifferentiated cells using the $2^{-\Delta \Delta \mathrm{CT}}$ method.(22)

Western Blotting: During differentiation, Triton X-100 solubilized protein was isolated from cells every two 2 days, from day 0 to day 14 . Cells were harvested in $50 \mathrm{mM}$ Tris, $\mathrm{pH}$ 7.4 containing $1 \%$ Triton X-100, Protease Inhibitor Cocktail I (Sigma-Aldrich, UK) and Phosphatase Inhibitor Cocktail 2 and placed on ice for $30 \mathrm{~min}$. Following centrifugation (10 min, 13,000g), protein content in the supernatant was determined using a BCA protein Assay Kit (Thermo Scientific). Samples containing $5 \mu \mathrm{g}$ of protein were separated on a NuPAGe 4-12\% Bis-Tris Gel (Invitrogen) and transferred to a PVDF membrane. NEP was detected using an anti-human NEP mouse monoclonal antibody (Novocastra), a rabbit antimouse horseradish peroxidise conjugate (Dako) and enhanced chemiluminescent reagent (Thermo-Scientific). Fold changes in NEP expression relative to undifferentiated cells were calculated from the signal intensities derived using Kodak 1D software (version 3.6).

\section{c) Neprilysin expression in a murine model of obesity}

Murine husbandry-Male C57BL/6J mice (Charles River Laboratories, Margate, UK) were bred and housed in a temperature controlled facility with a $12 \mathrm{~h} \mathrm{light/dark} \mathrm{cycle.} \mathrm{Mice}$ $(\mathrm{n}=8)$ were fed a high-fat diet (HFD) $(5,286 \mathrm{kcal} / \mathrm{kg} ; 60 \% \mathrm{kcal}$ from fat; Bioserve) from weaning onwards for 15 weeks. Control animals $(n=8)$ received a normal chow diet (NCD). All mice had free access to drinking water and food. Body weight was recorded weekly. At 14 weeks on HFD animals were metabolically phenotyped including an intraperitoneal glucose tolerance test (GTT) using a dose of $1 \mathrm{mg}$ glucose/g body weight and an insulin tolerance test (ITT) by the intraperitoneal injection of 0.5 unit human recombinant insulin / $\mathrm{kg}$ body weight. Tail vein blood was used for glucose quantification using a Glucometer (Roche Accucheck) during GTT and ITT. After 15 weeks, animals were sacrificed, mesenteric, epididymal and perirenal adipose tissue, liver, and kidney were harvested, and weights of epididymal fat pads were recorded. Tissues were snap frozen in liquid nitrogen and stored at $-80^{\circ} \mathrm{C}$. All procedures were performed in accordance with the U.K.. Guidance on the Operation of the Animals (Scientific Procedures) Act (1986).

Murine plasma and tissue levels of neprilysin-After 7 and 15 weeks of HFD, mice were bled from the lateral saphenous vein. Blood was collected in Microvette lithium heparin 300 tubes (Sarstedt, UK) and centrifuged for $10 \mathrm{~min}$ at 11,336 g. Plasma was stored at $-80^{\circ} \mathrm{C}$. NEP protein levels were measured using the NEP mouse DuoSet kit (R \& D Systems, Abingdon, UK) following the manufacturer's instructions. Plasma was diluted 2.66-fold with phosphate buffered saline (PBS: $137 \mathrm{mM} \mathrm{NaCl}, 2.7 \mathrm{mM} \mathrm{KCl}, 8.1 \mathrm{mM}$ $\mathrm{Na}_{2} \mathrm{HPO}_{4}, 1.5 \mathrm{mM} \mathrm{KH}_{2} \mathrm{PO}_{4}, \mathrm{pH} 7.4$ ) containing $20 \%$ fetal calf serum.

To measure NEP protein levels in liver, kidney, epididymal, mesenteric and perirenal fat, $100 \mathrm{mg}$ tissue per organ was homogenised $50 \mathrm{mM}$ Tris, $\mathrm{pH} 7.4,100 \mathrm{mM} \mathrm{NaCl}$ and $0.5 \%$ Triton-X100. Tissues were disrupted by rapid agitation using a Qiagen TissueLyser (Qiagen, 
Crawley, UK) in tubes containing stainless steel cones. The homogenate was incubated on ice for $60 \mathrm{~min}$ and centrifuged at $2004 \mathrm{~g}$ for $60 \mathrm{~min}$. The supernatant was diluted 8-fold with PBS containing $20 \%$ fetal calf serum. Total protein levels were measured using a BCA protein assay kit (Thermo Scientific) and results were expressed as a ratio of ng NEP /mg total protein. The results are presented as median and $25^{\text {th }}$ and $75^{\text {th }}$ percentiles.

\section{d) Metabolic characteristics of NEPKO mice in a high fat feeding model}

In a separate set of experiments, breeding colonies between NEPKO (23) and C57BL/6J mice were established, and male littermates were subjected twice to glucose and insulin tolerance tests as described above. Equally, their final body and epididymal fat pat weights were recorded. For this study, 10 NEPKO and 8 wild type littermates were subjected to normal chow whilst 7 NEPKO and 10 wild type litermates received the high fat food decribed above.

\section{Statistical Analyses}

In the clinical study, age, cholesterol, low density lipoprotein (LDL) cholesterol, SBP, DBP, waist:hip ratio (WHR) and waist circumference and tPA were normally distributed, and data are presented as mean and 95\% confidence intervals. BMI, HDL cholesterol, triglycerides, insulin, glucose, HOMA, fibrinogen and PAI-1 were log transformed to normalise their distributions for analysis, with data presented as geometric mean and $95 \%$ confidence intervals. Individuals with NEP at or below $(n=18)$ the lower limit of detection (LLD) were assigned the LLD value of $0.0027 \mathrm{nmol} / \mathrm{L}$. NEP did not have a normal distribution even after log transformation and NEP data was analysed by non-parametric analyses with data presented as a median ( $25^{\text {th }}$ and $75^{\text {th }}$ percentiles). Categorical data were analysed by $\chi^{2}$ test. Differences in clinical characteristics between subjects with and without the metabolic syndrome were assessed by independent student $t$-test for normally distributed variables and by Mann Whitney $U$ test for variables that were not normally distributed. Mann Whitney U tests were employed to determine the association between NEP and components of the metabolic syndrome. The relationship between NEP and the number of features of the metabolic syndrome was assessed by Kruskal-Wallis test and bivariate Spearman rank correlation was used to establish the associations between NEP and other cardiovascular risk factors. For linear regression analysis to identify determinants of NEP, those with NEP below the threshold were excluded and NEP was log-transformed to a normal distribution for analysis using forwards stepwise selection. Receiver Operating Characteristic (ROC) curve analysis was used to determine a cut-point for NEP in relation to MetS $\mathrm{S}_{\mathrm{IDF}}$; on the basis of this analysis NEP was dichotomised according to NEP $<0.2028 \mathrm{nmol} / \mathrm{L}$ or $\geq 0.2028$ $\mathrm{nmol} / \mathrm{L}$ for further analysis. Logistic regression analysis was utilised to identify factors predicting the presence of metabolic syndrome and its sub-components, with data presented as odds ratio (OR) and 95\% confidence intervals. All analyses were performed using SPSS for Windows version 12.0 (SPSS Inc, Chicago, Illinois, USA).

Results of the experimental studies are reported as mean \pm SEM, unless otherwise stated. Differences were analysed by t-test or in the case of non-normal distribution by MannWhitney $U$-test. A probability value $<0.05$ was regarded as significant.

\section{Results}

\section{Neprilysin activity is associated with metabolic syndrome, insulin resistance and cardiovascular risk factors in human subjects}

The clinical and biochemical characteristics of the 318 subjects according to the presence of the metabolic syndrome are presented in Table 1. Seventy nine subjects (24.8\%) fulfilled the IDF criteria for exhibiting the MetS, 229 subjects (75.2\%) did not have the MetS by these 
criteria. Subjects with the MetS $\mathrm{S}_{\mathrm{IDF}}$ were slightly older with significantly higher BMI, cholesterol, LDL, insulin and HOMA than those without the MetS $\mathrm{S}_{\text {IDF. The haemostatic }}$ factors PAI-1 and tPA were also significantly higher in subjects with the MetS IDF. The prevalence of smoking and family history of cardiovascular disease was similar in the two groups. Plasma NEP concentration was significantly associated with BMI ( $\mathrm{p}$ for trend $<0.0001)$ increasing from a median $\left(25^{\text {th }}\right.$ and $75^{\text {th }}$ percentiles $)$ of $0.155(0.048,0.310) \mathrm{nmol} /$ $\mathrm{L}$ in those with BMI $<25 \mathrm{~kg} / \mathrm{m}^{2}$ to $0.358(0.233,0.719) \mathrm{nmol} / \mathrm{L}$ ( $\left.\mathrm{p}<0.001\right)$ in those with BMI $>30 \mathrm{~kg} / \mathrm{m}^{2}$ (Fig 1A). Similarly, there was a stepwise increase in NEP concentration with increasing quartiles of HOMA (Fig 1B), however, only the difference in NEP between quartiles 4 and 1 were significant after adjustment of age, sex and BMI (adjusted NEP levels: 0.199 [0.150, 0.265] nmol/L in HOMA quartile 1 vs. $0.366[0.275,0.488] \mathrm{nmol} / \mathrm{L}$ in HOMA quartile $4, \mathrm{p}=0.015$ after adjustment for multiple comparisons). NEP activity was significantly higher in subjects with the $\mathrm{MetS}_{\mathrm{IDF}}$ compared to those without ( 0.38 vs 0.2 $\mathrm{nmol} / \mathrm{L}$, respectively, $\mathrm{p}<0.001$ ), and increased progressively with the number of MetS $\mathrm{S}_{\mathrm{IDF}}$ components, being $\sim 8$-fold higher in those with $5 \mathrm{Met} \mathrm{S}_{\mathrm{IDF}}$ components compared with those with no MetS $\mathrm{SDF}_{\mathrm{IDF}}(\mathrm{p}<0.0001$ after Bonferroni adjustment for multiple comparisons, Figure 2A). NEP was also significantly higher in subjects with a family history of cardiovascular disease $(0.18$ vs $0.30 \mathrm{nmol} / \mathrm{L}$, respectively, $\mathrm{p}<0.001)$. Plasma NEP correlated with fasting insulin $(r=0.3, p<0.001)$, HOMA $(r=0.3, p<0.001)$, BMI $(r=0.34, p<0.001)$, tPA $(r=0.44$, $\mathrm{p}<0.001)$ and PAI-1 $(\mathrm{r}=0.41, \mathrm{p}<0.001)$ in all subjects. In a linear regression analysis (excluding subjects with NEP below the assay threshold), significant predictors of plasma NEP concentration were triglyceride, tPA, DBP and PAI-1, which together explained 25\% of variance in NEP. ROC curve analysis was used to determine a cut-point for NEP in relation to $\mathrm{MetS}_{\mathrm{IDF}}$ (see figure 2B, inset); on the basis of this analysis NEP was dichotomised according to NEP $<0.2028 \mathrm{nmol} / \mathrm{L}$ or $\searrow 0.2028 \mathrm{nmol} / \mathrm{L}$ for further analysis. Logistic regression analysis, with backwards stepwise selection for cardiovascular risk factors not directly contributing to the MetS definition, including NEP cut-point, age, smoking, HOMA, LDL, PAI-1 and tPA, was carried out. This analysis indicated that NEP was independently associated with $\mathrm{MetS}_{\mathrm{IDF}}$ (OR for NEP $\searrow 0.2028 \mathrm{nmol} / \mathrm{L}, 2.31[1.14$, 4.66], $\mathrm{p}=0.02$ ) and each of the MetS subcomponents (Figure 2B).

\section{NEP mRNA levels are increased during differentiation of human adipocytes}

As shown in Figure 3A, human SGBS pre-adipocytes expressed NEP mRNA (CT value approximately 25 ), and this was increased $~ 25-30$-fold, during adipocyte differentiation. At the protein level, NEP was similarly increased when human SGBS preadipocytes differentiated into mature adipocytes (Figure 3B). To examine the expression levels of SGBS adipocyte-derived NEP, Affymetrix human 133 plus 2 gene chip arrays (47,400 transcripts) of differentiating SGBS cells indicated expression of NEP mRNA at levels comparable to that of known adipokines such as adiponectin, retinol binding protein 4 and PAI-1 (Figure 3C) and at least five times higher than the average gene signal.

\section{Neprilysin plasma levels are higher in obese HFD-fed mice}

Male C57BL/6J mice fed NCD or HFD, showed significant differences in weight after 6 weeks and at 14 weeks total body weight was $34.1 \pm 3.0 \mathrm{~g}$ and $47.6 \pm 1.8 \mathrm{~g}$, respectively $(\mathrm{p}<0.05)$. At the end of the feeding period, there was an increase in epididymal, mesenteric and perirenal fat by $47.5 \%, 29.5 \%$ and $25.9 \%$ respectively, in the HFD-fed mice compared with NCD-fed mice (data not shown). Metabolic characterisation and determination of NEP levels was performed on mice after 14 weeks of diet. As described previously (27), HFD-fed mice exhibited a significant impairment in glucose tolerance compared with mice fed NCD. Consistently, insulin sensitivity was impaired at this time point $(n=8 ; p<0.05)$ (data not shown). In parallel to the increase in body weight and the impairment in glucose homeostasis, plasma NEP levels were significantly higher in HFD-fed mice both at 7 and 15 
weeks of diet compared to NCD-fed mice (15 weeks: HFD: $1642 \pm 529 \mathrm{pg} / \mu \mathrm{l}, \mathrm{NCD}: 820 \pm$ $487 \mathrm{pg} / \mu \mathrm{l} ; \mathrm{p}<0.01)$. Furthermore the increase in NEP plasma levels comparing 7 and 15 weeks was significant in HFD-fed mice, but not in NCD-fed mice $(n=8 ; p<0.05)$ (Figure $4 \mathrm{~A})$. NEP tissue levels at 15 weeks were significantly higher in mesenteric adipose tissue of HFD-fed mice compared with NCD-fed mice ( $n=8 ; p<0.05)$, but no significant changes in NEP levels in epididymal, perirenal, liver or kidney tissue were observed (Figure 4B).

\section{NEP knock out does not lead to changes in metabolic characteristics in normal chow and high fat fed mice}

We investigated the effect of NEP deficiency on glucose and insulin tolerance and total and epididymal fat pad weight and found no difference between NEPKO and wild type littermates on either diet (figure 5). Both NEPKO and WT HFF mice differed significantly to NCF mice in all parameters ( $\mathrm{p}<0.05)$ (Figure 5).

\section{Discussion}

Substantial interest has been generated in the factors involved in the development of the tight relationship between insulin resistance, type 2 diabetes and cardiovascular disease and much attention has been focussed on the role of the adipocyte in these processes. Clinically, the appearance of obesity seems to drive the development of insulin resistance in many individuals and this is often associated with clustering of cardiometabolic risk factors. NEP fulfils some of the criteria for having a role in cardiometabolic risk: data indicates that it is expressed by the adipocyte and has a role in blood pressure regulation and in animal studies there are indications that NEP inhibition is associated with enhanced insulin sensitivity. (9-11) There are also data indicating that NEP cleaves GLP-1(24), suggesting potential for an influence on insulin secretion in addition to insulin sensitivity, but the relative clinical importance of these effects requires elucidation. In a previous study, we have observed significant correlations between circulating levels of NEP and the presence of the MetS and hypertension, as well as levels of triglyceride. (16) In the present study we have confirmed that NEP is independently associated with $\mathrm{MetS}_{\mathrm{IDF}}$ and its sub-components, increasing progressively with BMI, HOMA and increasing number of MetS components, and that NEP correlated with haemostatic cardiovascular risk factors, extending our original observations. The clinical association between NEP and cardiovascular risk raises the question as to whether these findings reflect association or causation. In addition to lipid storage, adipose tissue acts as an endocrine organ releasing adipokines and cytokines including adiponectin, tumour necrosis factor (TNF)- $a$ and interleukin (IL)-6.(25) NEP expression has previously been demonstrated on the surface of isolated pre-adipocytes and adipocytes (8) and we employed SGBS cells, a human preadipocyte cell line with high capacity for adipose differentiation to evaluate adipocyte NEP expression in vitro.(21) We interrogated microarray data from 14-day differentiated SGBS adipocytes and revealed expression levels of NEP higher than most other genes, and of the same order of magnitude as adiponectin and PAI-1, which are established adipokines. We also found a 28-fold increase in NEP mRNA expression and a 13-fold increase in NEP protein expression during a 14-day time-course of adipocyte differentiation. These data are in support of a previous study by Moro et al. who found a progressive increase in NEP mRNA and protein levels during human preadipocyte differentiation. (26) However, NEP is not required for adipose differentiation in vivo, as we observed that NEP knock out mice both under normal and high fat feeding conditions did not vary substantially in total body or epididymal fat pad weight.

The hypothesis that NEP expression in differentiated adipocytes provides a source for circulating NEP is supported by our murine data that demonstrated comparable NEP protein expression in adipose tissue and kidney in NCD-fed mice. We demonstrated that plasma NEP concentration increased as obesity and insulin resistance developed in HFD-fed mice, a 
change mirrored by increased protein expression of NEP in adipose tissue, in particular in mesenteric fat. In contrast, no significant increase in NEP protein expression was observed in kidney and liver under these circumstances. It would be important to evaluate whether increasing obesity drives adipocyte NEP expression in humans in an analogous manner.

There are two mechanisms by which NEP could contribute to increased insulin resistance. First, it cleaves bradykinin, which has an important role in the modulation of glucose metabolism in peripheral tissues. In adipocytes, bradykinin increases insulin sensitivity by enhancing GLUT4 translocation, IRS-1 phosphorylation, the interaction of IRS-1 association with the p85 regulatory subunit of PI3 kinase and phosphorylation of $\mathrm{Thr}^{308}$ and Ser $^{473}$ of Akt/PKB. $(27 ; 28)$ The observed increase of bradykinin in the presence of ACE inhibition has been described as a possible mechanism for ACE inhibitor-induced increased insulin sensitivity. An increase in NEP could lead to an imbalance in bradykinin induced regulation of glucose uptake in the cell, thereby contributing to insulin resistance. Second, studies in cancer cell models have demonstrated that the intracellular domain of NEP directly interacts with phosphatase and tensin homologue (PTEN) tumour suppressor protein. Contact between the negatively charged phosphorylated region in the C-terminus of PTEN and a cationic alkaline stretch in the N-terminal intracellular tail of NEP targets PTEN to the cell membrane and enhances its stability and phosphatase activity leading to a decrease in insulin signalling via the PI3/Akt axis. (29) However, our studies of a diet induced model of obesity in mice deficient of NEP did not result in a change in glucose tolerance and insulin sensitivity compared to wild type littermates fed the same diet, suggesting that the increased NEP observed in the wild type high fat feeding model is not a cause of insulin resistance. Increases in plasma NEP could still be responsible for pathophysiological changes observed in insulin resistance. The published literature strongly supports a role for systemic NEP in the regulation of blood pressure: in both human studies and animal models dual ACE/NEP inhibition was more beneficial in reducing blood pressure than ACE inhibition alone (30;31), whilst treating normotensive subjects with a dual ACE/NEP inhibitor resulted in favourable renal hemodynamic effects including a reduction in blood pressure. (32) These data indicate that NEP has additional or independent effects on blood pressure over and above ACE, supporting our observation of an independent association between NEP and elevated blood pressure in the current work. A mechanism linking increased NEP activity in plasma to hypertension could be provided by increased degradation of vasoactive peptides such as bradykinin or the natriuretic peptides, leading to endothelial dysfunction, decreased vaso-relaxation and elevated blood pressure. In support of this, recent animal studies have shown that candoxatril, a specific NEP inhibitor, improves endothelial dysfunction and reduces intimal hyperplasia as well as PAI-1 production. (33)The in vitro observation that addition of fatty acids or glucose to human microvascular endothelial cells increases NEP activity $(34 ; 35)$ raises the possibility that metabolic cycling from euglycaemic insulin resistance through to type 2 diabetes may provide the hyperglycaemic and dyslipidaemic environment to further enhance the deleterious vascular effects associated with local upregulation of NEP, with detrimental consequences on endothelial function, and further predisposition to cardiovascular disease.

In conclusion, the present study has shown that obesity and the development of insulin resistance are associated with increased plasma and adipose tissue NEP levels and that there is an increase in NEP expression during adipocyte differentiation. The relationship of NEP to dyslipidaemia, and elevated blood pressure independent of insulin resistance supports pleiotropic effects of NEP in relation to cardiovascular risk, which may be partly mediated by the development of endothelial dysfunction. 


\section{Limitations of our study}

Although we have shown in our murine model of obesity that NEP increases in fat tissue and plasma as a consequence of high fat feeding, we have no direct evidence that circulating NEP is derived from adipocytes, or that soluble NEP represents NEP activity in tissues, even though our study suggests that this could be a possibility. We have shown that in our cell culture experiments, NEP gene and protein expression increases significantly during cell differentiation, but, in preliminary experiments using phorbol ester and calcium ionophore to stimulate shedding of membrane bound NEP, we were unable to detect release of NEP from SBGS cells into culture medium under these experimental conditions (data not shown). Thus, it appears that if adipocytes significantly contribute to plasma levels of soluble NEP, it would be highly likely that release of NEP from the adipocyte involves an extracellular signal activating the appropriate cell surface sheddase mechanism. We are currently carrying out further work to explore this possibility. We chose to use SGBS cells to carry out cell culture experiments, because they offer an almost unlimited source of preadipocytes. SGBS cells are a widely accepted tool for the study of human adipocyte biology, reported by previous publications as comparable to isolated primary human preadipocytes. (36)

\section{Acknowledgments}

Funding Sources: This study was partially funded by British Heart Foundation grant no. PG/02/106/14434. Katharina Hess is supported by a grant from the German ADUMED foundation.

\section{References}

(1). Turner AJ, Isaac RE, Coates D. The neprilysin (NEP) family of zinc metalloendopeptidases: genomics and function. Bioessays. 2001; 23(3):261-269. [PubMed: 11223883]

(2). Turner, AJ. Neprilysin. In: Barret, AJ.; Rawlings, ND.; Woessner, JF., editors. Handbook of Proteolytic Enzymes. Elsevier; Amsterdam: 2004. p. 419-426.

(3). Corti R, Burnett JC Jr. Rouleau JL, Ruschitzka F, Luscher TF. Vasopeptidase inhibitors: a new therapeutic concept in cardiovascular disease? Circulation. 2001; 104(15):1856-1862. [PubMed: 11591626]

(4). Molinaro G, Rouleau JL, Adam A. Vasopeptidase inhibitors: a new class of dual zinc metallopeptidase inhibitors for cardiorenal therapeutics. Curr Opin Pharmacol. 2002; 2(2):131141. [PubMed: 11950623]

(5). Campbell DJ. Vasopeptidase inhibition: a double-edged sword? Hypertension. 2003; 41(3):383389. [PubMed: 12623931]

(6). Kostis JB, Packer M, Black HR, Schmieder R, Henry D, Levy E. Omapatrilat and enalapril in patients with hypertension: the Omapatrilat Cardiovascular Treatment vs. Enalapril (OCTAVE) trial. Am J Hypertens. 2004; 17(2):103-111. [PubMed: 14751650]

(7). Azizi M, Lamarre-Cliche M, Labatide-Alanore A, Bissery A, Guyene TT, Menard J. Physiologic consequences of vasopeptidase inhibition in humans: effect of sodium intake. J Am Soc Nephrol. 2002; 13(10):2454-2463. [PubMed: 12239234]

(8). Schling P, Schafer T. Human adipose tissue cells keep tight control on the angiotensin II levels in their vicinity. J Biol Chem. 2002; 277(50):48066-48075. [PubMed: 12196514]

(9). Arbin V, Claperon N, Fournie-Zaluski MC, Roques BP, Peyroux J. Acute effect of the dual angiotensin-converting enzyme and neutral endopeptidase 24-11 inhibitor mixanpril on insulin sensitivity in obese Zucker rat. Br J Pharmacol. 2001; 133(4):495-502. [PubMed: 11399666]

(10). Arbin V, Claperon N, Fournie-Zaluski MC, Roques BP, Peyroux J. Effects of dual angiotensinconverting enzyme and neutral endopeptidase $24-11$ chronic inhibition by mixanpril on insulin sensitivity in lean and obese Zucker rats. J Cardiovasc Pharmacol. 2003; 41(2):254-264. [PubMed: 12548087]

(11). Wang CH, Leung N, Lapointe N, Szeto L, Uffelman KD, Giacca A, et al. Vasopeptidase inhibitor omapatrilat induces profound insulin sensitization and increases myocardial glucose uptake in Zucker fatty rats: Studies comparing a vasopeptidase inhibitor, angiotensin-converting enzyme 
inhibitor, and angiotensin II type I receptor blocker. Circulation. 2003; 107(14):1923-1929. [PubMed: 12668518]

(12). Spillantini MG, Sicuteri F, Salmon S, Malfroy B. Characterization of endopeptidase 3.4.24.11 ("enkephalinase") activity in human plasma and cerebrospinal fluid. Biochem Pharmacol. 1990; 39(8):1353-1356. [PubMed: 2322317]

(13). Yandle T, Richards M, Smith M, Charles C, Livesey J, Espiner E. Assay of endopeptidase-24.11 activity in plasma applied to in vivo studies of endopeptidase inhibitors. Clin Chem. 1992; 38(9): 1785-1791. [PubMed: 1526015]

(14). Jalil JE, Ocaranza MP, Oliveri C, Cordova S, Godoy I, Chamorro G, et al. Neutral endopeptidase and angiotensin I converting enzyme insertion/deletion gene polymorphism in humans. J Hum Hypertens. 2004; 18(2):119-125. [PubMed: 14730327]

(15). Simonini G, Azzari C, Gelli AM, Giani T, Calabri GB, Leoncini G, et al. Neprilysin levels in plasma and synovial fluid of juvenile idiopathic arthritis patients. Rheumatol Int. 2005; 25(5): 336-340. [PubMed: 14997340]

(16). Rice GI, Jones AL, Grant PJ, Carter AM, Turner AJ, Hooper NM. Circulating activities of angiotensin-converting enzyme, its homolog, angiotensin-converting enzyme 2 , and neprilysin in a family study. Hypertension. 2006; 48(5):914-920. [PubMed: 17000927]

(17). Parry DJ, Grant PJ, Scott DJ. Atherothrombotic risk factor clustering in healthy male relatives of male patients with intermittent claudication. J Vasc Surg. 2004; 40(5):891-898. [PubMed: 15557902]

(18). Parry DJ, Grant PJ, Scott DJ. Fibrinolytic risk factor clustering and insulin resistance in healthy male relatives of men with intermittent claudication. Br J Surg. 2006; 93(3):315-324. [PubMed: 16498597]

(19). Mumford RA, Pierzchala PA, Strauss AW, Zimmerman M. Purification of a membrane-bound metalloendopeptidase from porcine kidney that degrades peptide hormones. Proc Natl Acad Sci U S A. 1981; 78(11):6623-6627. [PubMed: 7031658]

(20). Zimmet P, Magliano D, Matsuzawa Y, Alberti G, Shaw J. The metabolic syndrome: a global public health problem and a new definition. J Atheroscler Thromb. 2005; 12(6):295-300. [PubMed: 16394610]

(21). Wabitsch M, Brenner RE, Melzner I, Braun M, Moller P, Heinze E, et al. Characterization of a human preadipocyte cell strain with high capacity for adipose differentiation. Int J Obes Relat Metab Disord. 2001; 25(1):8-15. [PubMed: 11244452]

(22). Weaver RE, Donnelly D, Wabitsch M, Grant PJ, Balmforth AJ. Functional expression of glucose-dependent insulinotropic polypeptide receptors is coupled to differentiation in a human adipocyte model. Int J Obes (Lond). 2008; 32(11):1705-1711. [PubMed: 18779825]

(23). Lu B, Gerard NP, Kolakowski LF Jr. Bozza M, Zurakowski D, Finco O, et al. Neutral endopeptidase modulation of septic shock. J Exp Med. 1995; 181(6):2271-2275. [PubMed: 7760013]

(24). Plamboeck A, Holst JJ, Carr RD, Deacon CF. Neutral endopeptidase 24.11 and dipeptidyl peptidase IV are both mediators of the degradation of glucagon-like peptide 1 in the anaesthetised pig. Diabetologia. 2005; 48(9):1882-1890. [PubMed: 16025254]

(25). Despres JP, Lemieux I. Abdominal obesity and metabolic syndrome. Nature. 2006; 444(7121): 881-887. [PubMed: 17167477]

(26). Moro C, Klimcakova E, Lafontan M, Berlan M, Galitzky J. Phosphodiesterase-5A and neutral endopeptidase activities in human adipocytes do not control atrial natriuretic peptide-mediated lipolysis. Br J Pharmacol. 2007; 152(7):1102-1110. [PubMed: 17906676]

(27). Velloso LA, Folli F, Perego L, Saad MJ. The multi-faceted cross-talk between the insulin and angiotensin II signaling systems. Diabetes Metab Res Rev. 2006; 22(2):98-107. [PubMed: 16389635]

(28). Carvalho CR, Thirone AC, Gontijo JA, Velloso LA, Saad MJ. Effect of captopril, losartan, and bradykinin on early steps of insulin action. Diabetes. 1997; 46(12):1950-1957. [PubMed: 9392479] 
(29). Sumitomo M, Iwase A, Zheng R, Navarro D, Kaminetzky D, Shen R, et al. Synergy in tumor suppression by direct interaction of neutral endopeptidase with PTEN. Cancer Cell. 2004; 5(1): 67-78. [PubMed: 14749127]

(30). Wallis EJ, Ramsay LE, Hettiarachchi J. Combined inhibition of neutral endopeptidase and angiotensin-converting enzyme by sampatrilat in essential hypertension. Clin Pharmacol Ther. 1998; 64(4):439-449. [PubMed: 9797801]

(31). Xu J, Carretero OA, Liu YH, Yang F, Shesely EG, Oja-Tebbe N, et al. Dual inhibition of ACE and NEP provides greater cardioprotection in mice with heart failure. J Card Fail. 2004; 10(1): 83-89. [PubMed: 14966779]

(32). Regamey F, Maillard M, Nussberger J, Brunner HR, Burnier M. Renal hemodynamic and natriuretic effects of concomitant Angiotensin-converting enzyme and neutral endopeptidase inhibition in men. Hypertension. 2002; 40(3):266-272. [PubMed: 12215465]

(33). Barber MN, Kanagasundaram M, Anderson CR, Burrell LM, Woods RL. Vascular neutral endopeptidase inhibition improves endothelial function and reduces intimal hyperplasia. Cardiovasc Res. 2006; 71(1):179-188. [PubMed: 16635483]

(34). Muangman P, Spenny ML, Tamura RN, Gibran NS. Fatty acids and glucose increase neutral endopeptidase activity in human microvascular endothelial cells. Shock. 2003; 19(6):508-512. [PubMed: 12785004]

(35). Muangman P, Tamura RN, Gibran NS. Antioxidants inhibit fatty acid and glucose-mediated induction of neutral endopeptidase gene expression in human microvascular endothelial cells. $\mathbf{J}$ Am Coll Surg. 2005; 200(2):208-215. [PubMed: 15664096]

(36). Fischer-Posovszky P, Newell FS, Wabitsch M, Tornqvist HE. Human SGBS Cells - a Unique Tool for Studies of Human Fat Cell Biology. Obes Facts. 2008; 1(4):184-189. [PubMed: 20054179] 

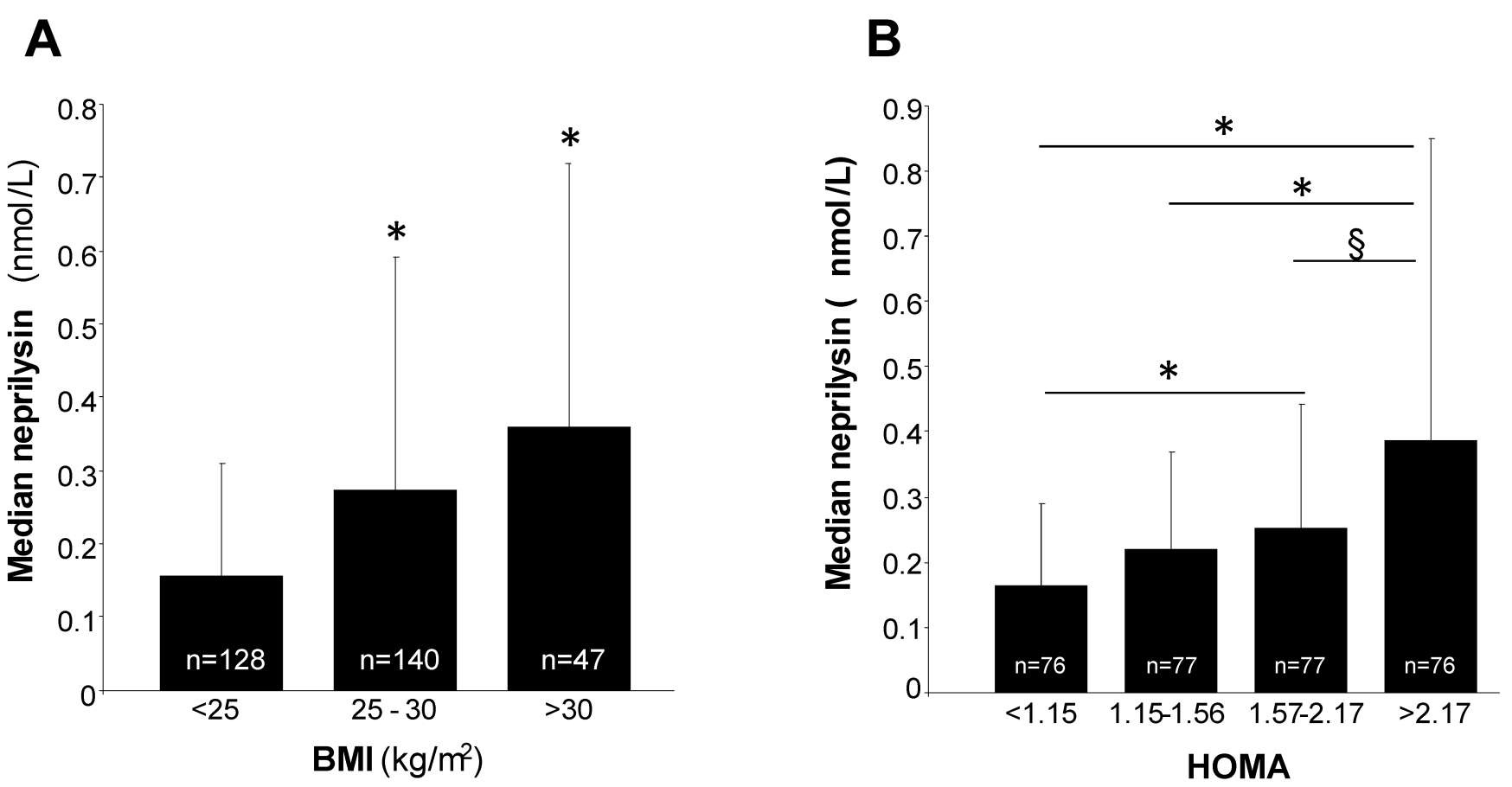

Figure 1. Relationship between plasma NEP, insulin resistance and BMI in healthy humans A: Plasma NEP is increased in overweight and obese subjects. Data presented as median and $75^{\text {th }}$ percentile; $*$ p $<0.0001$ comparing overweight (BMI 25-30) and obese subjects (BMI $>30$ ) with those with BMI <25 (after adjusting for multiple comparisons). B: Circulating NEP increases across increasing quartiles of HOMA. Data presented as median and $75^{\text {th }}$ percentile; * $\mathrm{p}<0.0001$ comparing quartiles 3 and 4 with quartile 1 and for comparing quartile 2 with 4 , and ${ }^{\S} \mathrm{p}=0.006$ comparing quartiles 3 with 4 (all after adjusting for multiple comparisons). 


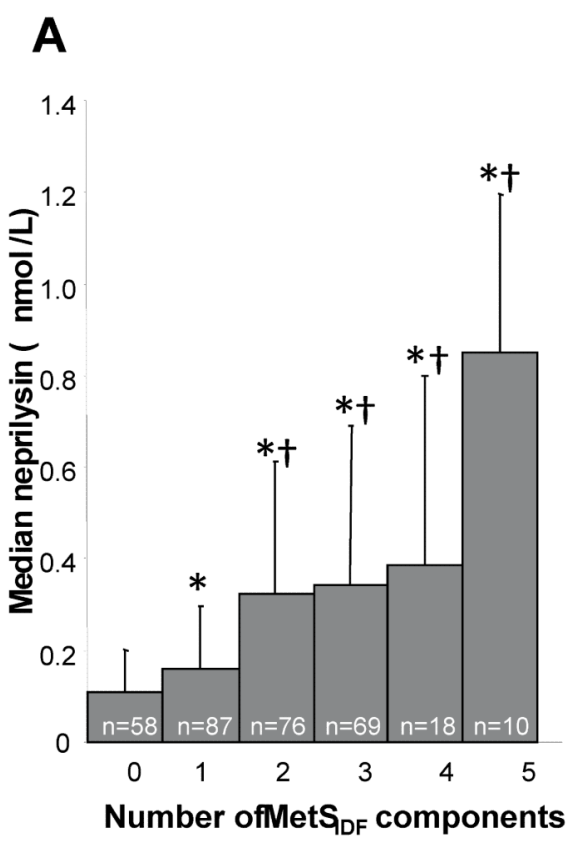

B

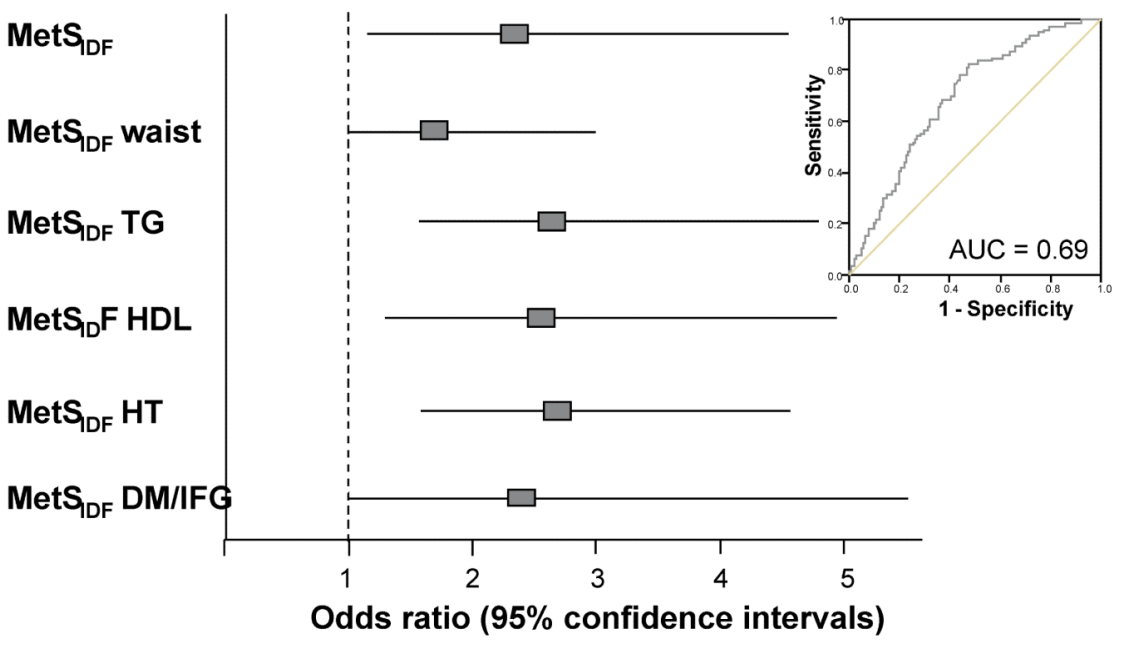

Figure 2. Relationships between NEP and the MetS in healthy subjects

A: NEP increased progressively with increasing number of MetS components $\mathrm{p}$ for trend $<0.0001$. Data presented as median NEP $\left(75^{\text {th }}\right.$ percentile) $(\mathrm{nmol} / \mathrm{L}) ; \mathbf{B}$ : NEP $\searrow 0.2028 \mathrm{nmol} /$

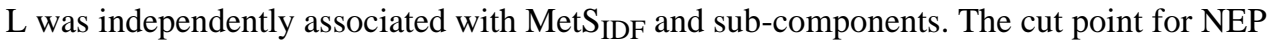
$\left(\searrow 0.2028 \mathrm{nmol} / \mathrm{L}\right.$ ) in relation to $\mathrm{MetS}_{\mathrm{IDF}}$ was determined from ROC curve analysis (inset). $* \mathrm{P}<0.0005$ compared with individuals with no MetS components after adjustment for multiple comparisons.

${ }^{\dagger} \mathrm{P}<0.001$ compared with individuals with one MetS component after adjustment for multiple comparisons. 
A

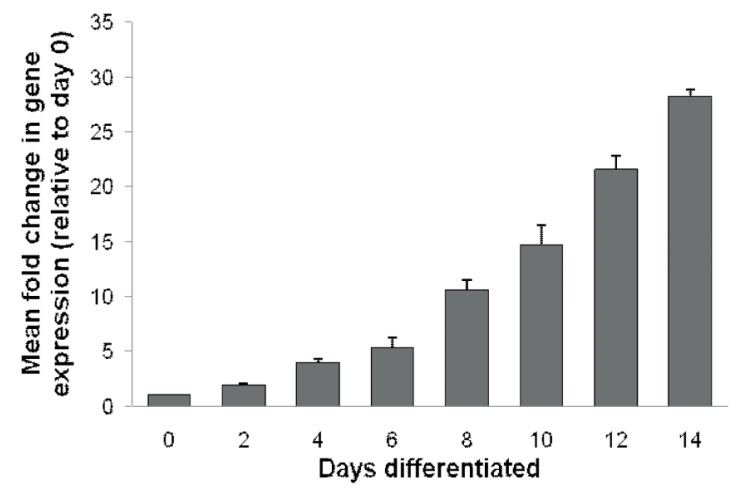

B

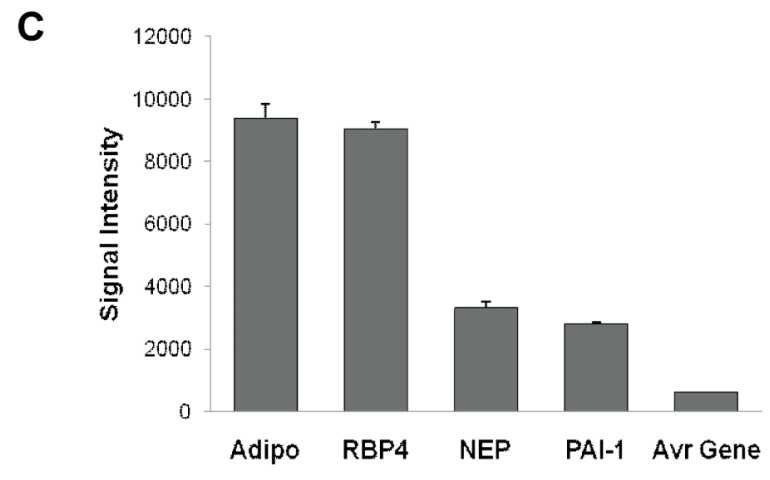

D

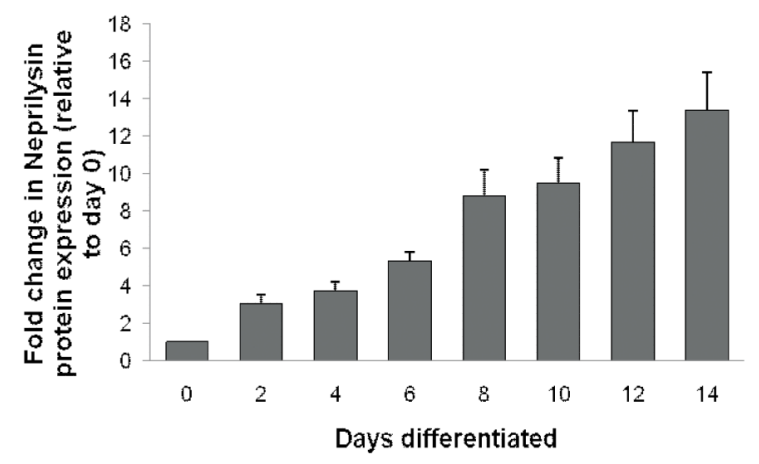

Od 2d $\quad 4 d \quad 6 d \quad 8 d \quad 10 d$ 12d 14dMWM

Figure 3. NEP expression in the human adipocyte SGBS cells during differentiation

Total RNA and total protein were extracted from differentiating SGBS cells over a 0-14 day period every 2 days, starting at day 0. A: NEP gene expression was measured using semiquantitative real time PCR, with simultaneous amplification of GAPDH as an internal control allowing normalisation of target gene expression. Data represents the mean values observed in two independent experiments, with samples analysed in triplicate. Data are presented as a fold increase in NEP gene expression, relative to the undifferentiated SGBS cells (day 0 ) which was readily detectable $\left(\mathrm{C}_{\mathrm{T}}\right.$ value approximately 25$)$. B: NEP protein expression was measured using a semiquantitative western blot approach. Data are presented as a fold increase in mean \pm SEM $(n=3)$ intensity values of NEP, relative to the undifferentiated SGBS cells (day 0). C: Gene expression of NEP, adiponectin, retinol binding protein-4 (RBP4) and PAI-1 in 14 day differentiated SGBS cells determined by the Human Genome U133 Plus 2.0 array. Data from nine arrays are represented as mean \pm SEM of the corresponding intensity signals derived by the GeneChip Operating Software. D:

Western blot showing the increase in NEP protein concentration over the $14 \mathrm{~d}$ differentiation period. 

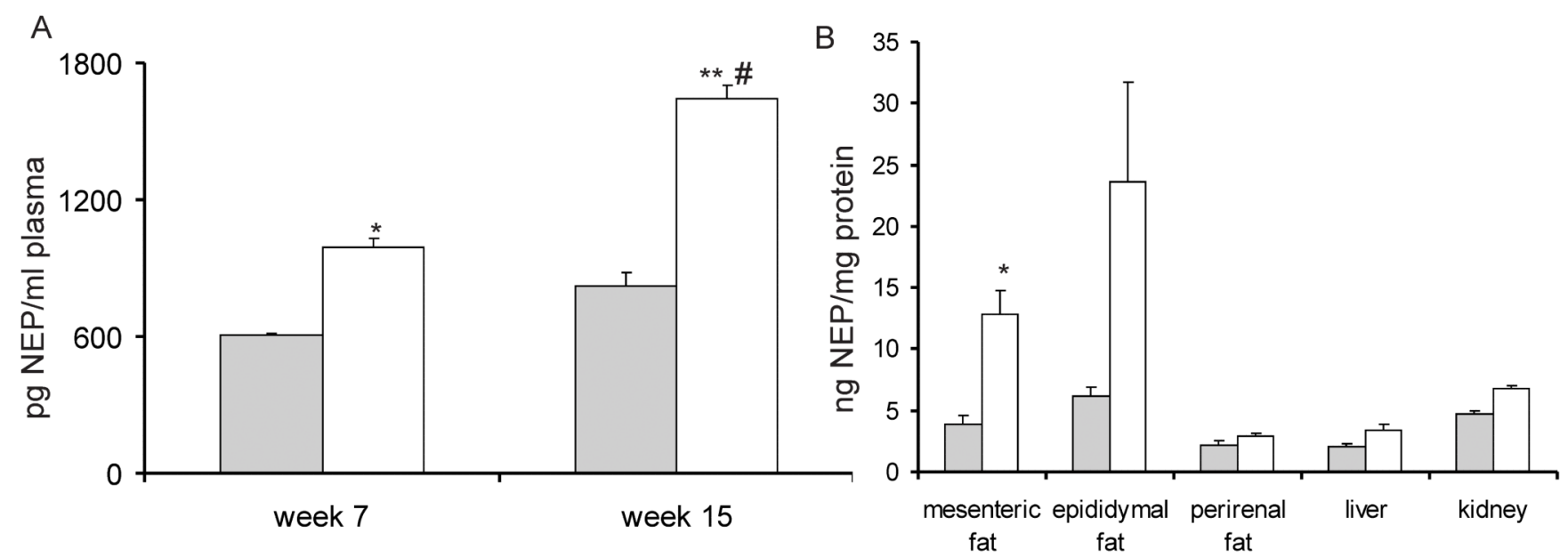

Figure 4. NEP plasma and tissue levels in a mouse model of high-fat diet (HFD) induced insulin resistance

A: After 7 and 15 weeks of diet, mice were bled from the lateral saphenous vein and NEP protein levels were measured. Grey bar: NCD-fed mice, white bar: HFD-fed mice. Results are presented as mean \pm SEM from $\mathrm{n}=8$ mice. $* \mathrm{p}<0.05$ vs. NCD, $* * \mathrm{p}<0.01$ vs. NCD, p<0.05 vs. HFD week 7. B: Tissues were harvested after 15 weeks of diet and NEP protein levels were measured in mesenteric adipose tissue (AT), epididymal AT, perirenal AT, liver, and kidney. Grey bar: NCD-fed, white bar: HFD-fed. NEP levels are expressed as a ratio of ng NEP to $m g$ total protein. Data are presented as median and $25^{\text {th }}$ and $75^{\text {th }}$ percentile from $\mathrm{n}=8$ mice. ${ }^{*} \mathrm{p}<0.05$ vs. NCD. 


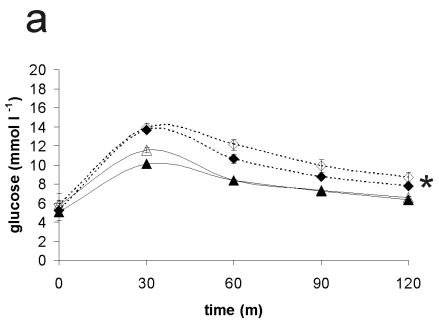

C
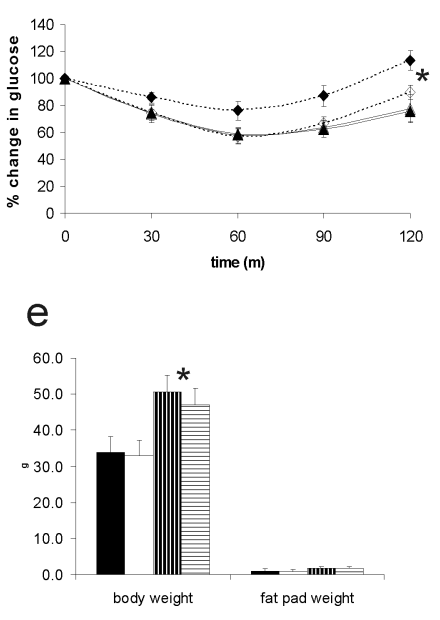

b

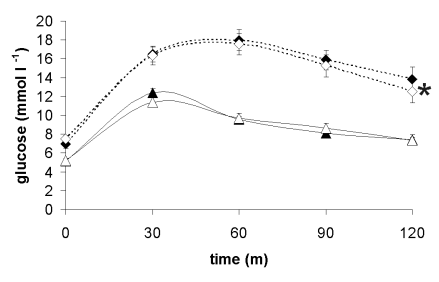

d

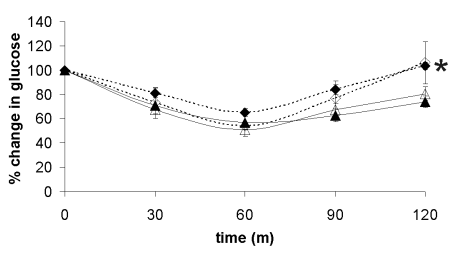

f

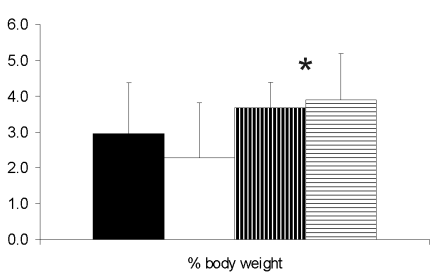

Figure 5. Metabolic characteristics of the NEPKO mouse under normal chow and high fat feeding regimes

Plasma glucose levels in response to intraperitoneal glucose administration (a, b) measured over 2 hours after 4 weeks (a) and 15 weeks (b) of feeding and in response to insulin administration (c,d) after 7 (c) and 20 (d) weeks of feeding; closed lines: NCF mice, dashed lines: HFF mice, open symbols: NEPKO, closed symbols WT littermates. There was no difference in response between NEPKO and WT. There was no change in e) body and fat pad weight after 20 weeks of feeding and $\mathrm{f}$ ) weight of epididymal fat pads (expressed as \% of total body weight); closed bars, wild type NCF, open bars, NEPKO NCF, horizontally striped bars WT HFF, vertically striped bars NEPKO HFF. In all parameters, HFF mice differed significantly from NCF mice $(* \mathrm{p}<0.05)$. 


\section{Table 1}

Characteristics of healthy male subjects categorised according to IDF definition of the metabolic syndrome $\left(\mathrm{MetS}_{\mathrm{IDF}}\right)$

\begin{tabular}{|c|c|c|c|}
\hline Clinical characteristics & No $\operatorname{MetS}_{\text {IDF }}(n=239)$ & $\operatorname{MetS}_{\text {IDF }}(n=79)$ & $p$ \\
\hline Age (years) & $40(39-41)$ & $42(40-44)$ & 0.03 \\
\hline Current smoker n $(\%)$ & $74(31)$ & $27(34)$ & 0.60 \\
\hline Family History of CVD n (\%) & $123(51)$ & $38(48)$ & 0.60 \\
\hline Waist circumference $(\mathrm{cm})$ & $88(87-89)$ & $102(100-104)$ & $<0.001$ \\
\hline $\mathrm{SBP}(\mathrm{mmHg})$ & $130(129-132)$ & $141(138,145)$ & $<0.001$ \\
\hline $\mathrm{DBP}(\mathrm{mmHg})$ & $79(78-81)$ & $86(84-89)$ & $<0.001$ \\
\hline Triglycerides (mmol/L) & $1.23(1.15-1.32)$ & $2.32(2.06-2.61)$ & $<0.001$ \\
\hline HDL cholesterol (mmol/L) & $1.33(1.29-1.37)$ & $1.08(1.03-1.13)$ & $<0.001$ \\
\hline Fasting glucose $(\mathrm{mmol} / \mathrm{L})$ & $4.86(4.79-4.92)$ & $5.39(5.20-5.59)$ & $<0.001$ \\
\hline $\operatorname{BMI}\left(\mathrm{kg} / \mathrm{m}^{2}\right)$ & $24.9(24.5-25.3)$ & $29.4(28.6-30.2)$ & $<0.001$ \\
\hline WHR $(\mathrm{cm})$ & $0.88(0.87-0.89)$ & $0.95(0.93-0.97)$ & $<0.001$ \\
\hline Cholesterol (mmol/L) & $5.4(5.2-5.5)$ & $5.9(5.6-6.2)$ & 0.001 \\
\hline LDL cholesterol (mmol/L) & $3.4(3.2-3.5)$ & $3.7(3.4-3.9)$ & 0.016 \\
\hline Insulin $(\mu \mathrm{U} / \mathrm{ml})$ & $6.6(6.1-7.0)$ & $8.8(7.6-10.3)$ & 0.001 \\
\hline HOMA & $1.4(1.3-1.5)$ & $2.1(1.8-2.5)$ & $<0.001$ \\
\hline $\mathrm{tPA}(\mathrm{ng} / \mathrm{ml})$ & $8.1(7.6-8.6)$ & $10.4(9.6-11.1)$ & $<0.001$ \\
\hline PAI-1 (ng/ml) & $7.8(6.9-8.8)$ & $17.1(14.1-20.9)$ & $<0.001$ \\
\hline Fibrinogen $(\mathrm{g} / \mathrm{l})$ & $2.88(2.79-2.97)$ & $3.05(2.90-3.22)$ & 0.067 \\
\hline
\end{tabular}

Data presented as mean or geometric mean $(95 \% \mathrm{CI})$, number (frequency) 